\title{
The diagnostic value of double-balloon enteroscopy in children with small bowel disease: Report of 31 cases
}

\author{
Wei Liu $M D^{1}$, Chundi Xu MD¹, Jie Zhong $M D^{2}$
}

\begin{abstract}
W Liu, C Xu, J Zhong. The diagnostic value of double-balloon enteroscopy in children with small bowel disease: Report of 31 cases. Can J Gastroenterol 2009;23(9):635-638.
\end{abstract}

BACKGROUND AND OBJECTIVE: Before the introduction of double-balloon enteroscopy (DBE), it was impossible to visualize the entire small bowel. Its diagnostic yield has been assessed in adults, but not yet in children. The present retrospective study evaluated the diagnostic usefulness and safety of DBE in children with suspected small bowel disease.

METHODS: Between June 2003 and June 2007, 31 patients (19 boys and 12 girls, age range three to 14 years) with suspected small bowel disease underwent DBE after receiving negative evaluations using other diagnostic modalities.

RESULTS: There were no severe complications. In two patients, the entire small bowel was viewed using oral and anal approaches, and for the remaining 29 patients, only one approach was used. The sites of disease in were identified in 25 of 31 cases $(80.65 \%)$. The bleeding source was found in 21 of 27 patients with obscure gastrointestinal bleeding (diagnostic rate of $77.78 \%$ ). Different diseases were identified in four children with chronic diarrhea.

CONCLUSION: DBE is a safe and effective method to diagnose patients with suspected small bowel disorders.

Key Words: Children; Double-balloon enteroscopy; Small bowel disease

Cmall bowel disease is not uncommon among children. However, because of its length (approximately $5 \mathrm{~m}$ ) and the difficulty in visualizing the small bowel in its entirety, it can be difficult to make a definitive diagnosis. Although gastroscopy and colonscopy are frequently used, the causes of most small bowel disease in children with abdominal pain, hematochezia or anemia cannot be identified. The usual techniques, such as angiography or scintigraphy, have low diagnostic yields without confirmation of the lesion sites. Double-balloon enteroscopy (DBE) enables the direct visualization of the entire small bowel as well as biopsy and treatment if indicated. To date, there are no reports of the use of DBE in children in China. The aim of the present retrospective study was to assess the diagnostic efficacy and safety of DBE in children suspected of having small bowel diseases.

\section{METHODS}

Between June 2003 and June 2007, 31 patients (19 boys, 12 girls; age range three to 14 years), with suspected small bowel disease, underwent DBE at the Ruijin Hospital, Shanghai, China. Of these 31 patients, 27 had relapsing obscure gastrointestinal

\section{La valeur diagnostique de l'entéroscopie à double ballonnet chez des enfants atteints d'une maladie de l'intestin grêle : exposé de}

\section{1 cas}

CONTEXTE ET BUT : Avant l'arrivée de l'entéroscopie à double ballonnet (EDB), il était impossible de visualiser l'intestin grêle sur toute sa longueur. Le champ diagnostique de l'examen a été évalué chez les adultes, mais pas chez les enfants. La présente étude rétrospective visait à évaluer l'utilité diagnostique et l'innocuité de l'EDB chez des enfants souffrant d'une maladie présumée de l'intestin grêle.

MÉTHODE : De juin 2003 à juin 2007, 31 patients (19 garçons et 12 filles; plage d'âge : 3 à 14 ans) atteints d'une maladie présumée de l'intestin grêle ont subi une EDB après que des examens de diagnostic eurent donné des résultats négatifs.

RÉSULTATS : Il ne s'est produit aucune complication grave. L'intestin grêle a été visualisé sur toute sa longueur, par voie orale et anale, chez deux malades, tandis qu'une seule voie a été utilisée chez les 29 autres malades. Le siège des lésions a été localisé dans 25 cas sur 31 (80,65 \%). On a trouvé la source d'hémorragies chez 21 enfants sur 27 présentant des saignements d'origine inconnue (taux de diagnostic : 77,78\%). Différentes maladies ont été diagnostiquées chez quatre enfants souffrant de diarrhée chronique. CONCLUSION : L'EDB est un examen sûr et efficace pour le diagnostic d'affections présumées de l'intestin grêle.

bleeding (OGIB) and four patients had chronic diarrhea. All of the patients had undergone various diagnostic procedures including gastroscopy, colonoscopy, barium swallow, abdominal computed tomography scanning and technetium-99m pertechnate scanning. Some had previously undergone angiography; however, there were no positive findings. All tests for liver function were normal and no hematological dysfunctions were identified.

\section{DBE}

The double-balloon enteroscope included a complete small bowel enteroscope (Fujinon EN-450 p5/20), an overtube (TS-12140), balloons (BS-1) and a special air pump (Fujinon Corporation, Japan). The enteroscope is similar in structure to an electronic colonoscope except that it has two balloons connected to an air pump - one is attached to the tip of the endoscope and the other to the distal end of the overtube. By using these balloons to grip the intestinal wall, the endoscope can be inserted further into the small bowel without forming redundant loops (1). This procedure is performed by two doctors while one nurse operates the air pump and monitors the

${ }^{1}$ Department of Pediatrics; ${ }^{2}$ Department of Gastroenterology, Ruijin Hospital, Shanghai Jiao Tong University, Shanghai, China

Correspondence: Dr Wei Liu, Department of Pediatrics, Ruijin Hospital, Shanghai Jiao Tong University School of Medicine,

Number 197 Ruijin Er Road, Shanghai 200025, China. Telephone 86-21-64370045-600905, fax 86-21-64370045,

e-mail chundixu@hotmail.com

Received for publication November 16, 2008. Accepted December 1, 2008 
TABLE 1

Results of double-balloon enteroscopy $(n=31)$

\begin{tabular}{llcl}
\hline Symptom & Underlying disease & Patients, $\mathbf{n}$ & Small intestine site \\
\hline Obscure gastrointestinal bleeding & Angioma & 7 & Jejunum, ileum \\
& Angiodysplasia & 2 & Jejunum, ileum \\
& Allergic purpura & 2 & Jejunum, ileum \\
& Duplication of small bowel & Ileum & Ileum \\
& Diverticulum & 1 & Jejunum \\
& Tumour & 1 & Jejunum, ileum, colon \\
& Peutz-Jeghers syndrome & 1 & Jejunum, ileum \\
Chronic diarrhea & Crohn's disease & 2 & - \\
& No positive findings & 5 & Duodenum, jejunum \\
& Lymphangiectasis & 6 & Jejunum, ileum \\
& Inflammatory bowel disease & 2 & Duodenum, jejunum, ileum \\
\hline
\end{tabular}

patient's vital signs. DBE is performed with either oral or anal approaches, depending on the patient's symptoms. Sequential inflation and deflation of the two anchoring balloons at the distal end of the enteroscope allows the enteroscope to proceed forward, which makes thorough examination of the small intestine possible. By labelling the end of the first insertion point with methylene blue, the operater can find the joining point after a change in the insertion route. The entire small bowel can be evaluated when DBE is performed using both oral and anal approaches.

\section{Depth of DBE insertion}

\section{RESULTS}

Of the 31 patients studied, the oral approach was used in 18 patients and the anal approach was used in 11 patients as the initial insertion route. DBE had successfully reached $2 \mathrm{~m}$ to $3 \mathrm{~m}$ beyond the ligament of Treitz using the oral approaches. The jejunum or jejunoileal junction was reached via the anal route. In two patients, the entire small intestine was viewed using both an oral and anal approach; procedure time ranged from $40 \mathrm{~min}$ to $70 \mathrm{~min}$.

\section{Diagnostic yield}

Lesion sites were identifined in 25 of 31 cases (80.65\%) using DBE. The source of bleeding was identified in 21 of 27 OGIB patients (a diagnostic rate of $77.78 \%$ ). Definitive diagnoses were made in four children with chronic diarrhea (Table 1). Specific endoscopic images of the small bowel captured with DBE are presented in Figure 1.

\section{Safety of DBE}

The procedure was successfully completed in all cases. Patients received intravenous anesthesia and there were no severe complications such as gastrointestinal perforation or bleeding. However, one child who underwent the procedure using the oral approach inspired a small amount of oral secretion. Throat complaints in children who underwent oral approches resolved quickly without any treatment.

\section{DISCUSSION}

The small bowel spans the stomach and colon, and is the longest part of the digestive tract. Because symptoms of small bowel diseases are nonspecific, the diagnostic yield of biopsies taken from this region are lagging behind that of other diagnostic procedures involving the digestive tract. The sensitivity and specificity of conventional diagnostic modalities such as small bowel barium swallow, radioisotopic scanning and selective arteriography are not high enough to make definitive diagnoses.

Small bowel barium swallow is useful for finding obstructive or space-occupying lesions, but not in mucosal disease or angiogenic lesions. Also, the result will vary with the experience of the operator. The reported diagnostic yield of barium swallow is approximately 20\% (2). Barium swallows in the present series were all negative. Scintiscanning may locate the bleeding site, but not if the bleeding rate is lower than $0.1 \mathrm{~mL} / \mathrm{min}$ or is intermittent. Selective angiography is invasive, but may be helpful in cases of angiodysplasia or tumours with effluent blood supply. We proceeded with angiography for some patients but had no yield.

Endoscopy is an innovation in the diagnosis and treatment of digestive diseases, while the use of wireless capsule endoscopy $(\mathrm{CE})$ and push DBE are novel investigational tools for detecting small bowel diseases.

There are many disadvantages to CE such as the uncontrollable movement of the capsule in the intestine, which may result in some valuable video images being overlooked. Its visibility and accuracy cannot be totally compared with that of conventional endoscopy, and biopsy is not possible (3); consequently, these limits affect the diagnostic value of $\mathrm{CE}$. We attempted CE in some children at our hospital; however, swallowing the capsule presented difficulties. Therefore, the use of CE is likely limited in children younger than 10 years of age.

The enteroscope used with DBE was invented by a Japanese scholar (Yamamoto [1]) and developed with the Fujinon Corporation of Japan. DBE consists of an endoscope incorporated with a soft flexible overtube, each with an inflatable balloon attached to its distal end. When inflated with air, the balloons can grip various sections of the small intestine and 'shorten' it by pleating it over the endoscope. Sequential inflation and deflation of the two balloons enable advancement of the endoscope, which allows for the visualization of the entire small bowel and offers the flexibility of 'back and forth' examination of any area of interest, and the ability to take biopsy specimens. The procedure is safer, quicker and less painful than previous techniques (4). Currently, experience with the use of DBE in adults to diagnose and treat small bowel diseases is accumulating (5-7), but its application in children remains limited. This is because a slender DBE system for children is not widely available and most pediatric gastroenterologists have no experience in performing the procedure. 

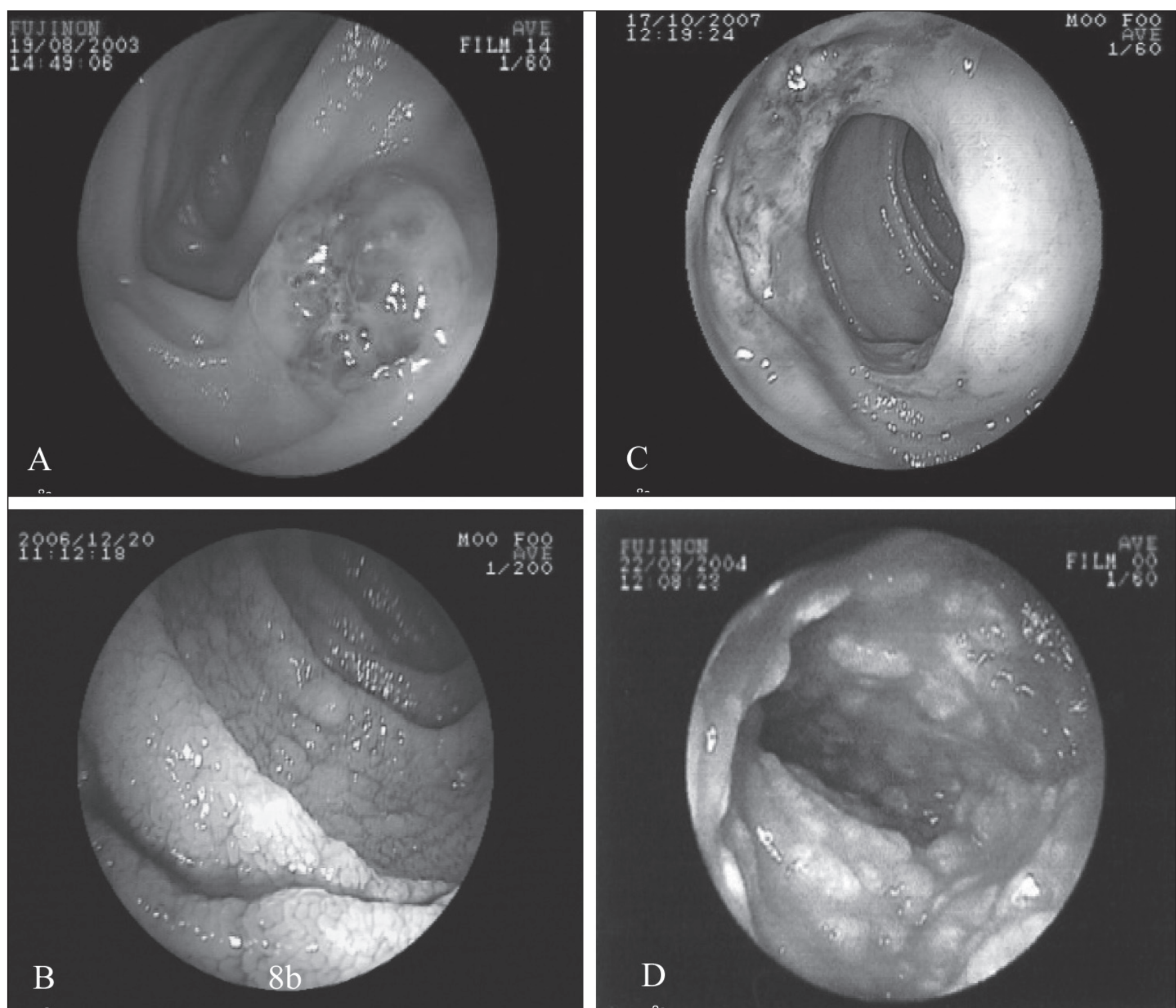

Figure 1) Endoscopic images of the small intestine harbouring different intestinal diseases. A Angioma of blue rubber bleb nevus syndrome. B Celiac disease, the 'scalloped' appearance was shown after dyeing with methylene blue. C Crohn's disease. D Intestinal lymphangiectasia

We are fortunate to be among the first users of DBE, performing the procedure since 2003. A total of 31 children have undergone the procedure successfully at our institution, the youngest of which was only three years of age. We have performed a total of 33 procedures, with approximately $50 \%$ to $60 \%$ of the length of the small intestine being visualized, although the procedure had to be stopped when obstructions in the small bowel were encountered. In our opinion, DBE in children is not only possible but also practical. Because DBE is usually a time-consuming procedure and the capacity of childrens' abdomens is much smaller than that of adults, we have never aimed to reach the ileocecal valve via the oral route or the duodenum via the retrograde approach in any of the 31 cases that have involved children.

DBE was performed using either oral (antegrade) or anal (retrograde) insertion, according to the estimated location of the lesion; antegrade insertion was used for suspected jejunal lesions and retrograde when an ileal lesion was suspected. In cases of highly suspicious small bowel disease, with no positive finding using one route, the other approach was used. When a lesion is found, we usually stop advancing and observe carefully while retreating the enteroscope slowly. Biopsies are usually taken and treatment administered to the patient if necessary. The entire procedure usually takes $40 \mathrm{~min}$ to $70 \mathrm{~min}$ to complete, not including anesthesia. According to our preliminary experience, the antegrade approach with DBE is easier to perform but is associated with some risk of inspiration of oral sections. The retrograde approach is somewhat more difficult but safer.

All of the procedures completed at our endoscopy centre in the present series were performed with intravenous anesthesia (1\% propofol, Fresenius SE, Germany). All children tolerated the procedure well, and there were no serious complications except one patient who had aspiration of oral secretions. The success rate of DBE is very high and the procedure is accepted by pediatricians. 
The diagnostic sensitivity and specificity of DBE is reasonably high. Lesions were found in 25 of 31 DBE cases, a diagnostic yield of $80.65 \%$. Bleeding sources were identified in the small bowel in 21 of 27 OGIB cases. The most common causes of OGIB were angioma and Crohn's disease. However, there were still six OGIB patients without an identified cause that needed further investigation. The probable reasons included bleeding sites not present in the small bowel, sites out of reach with DBE or inappropriate timing of the examination. Our interpretation of this new technique is that DBE is a feasible and useful diagnostic modality in children, especially those with small bowel diseases. It can supplement the commonly used diagnostic procedures used in children such as small bowel barium swallow, scintiscanning and angiography.

\section{CONCLUSION}

DBE is a safe and effective technique with a high diagnostic yield for intestinal mucosal pathology. However, currently its use remains limited due to the reasons described. The outer diameter of the enteroscope we used in the three-year-old child was $12.2 \mathrm{~mm}$, which involved higher risk. DBE is a new technique that is somewhat different from the commonly used procedures such as gastroscopy or colonscopy. Gastroenterologists need to be specially trained before using DBE in clinical practice. Pediatric gastroenterologists should be trained in a general hospital instead of a children's hospital to have more opportunites to practice the technique.

\section{REFERENCES}

1. Yamamoto H, Sekine Y, Sato Y, et al. Total enteroscopy with a nonsurgical steerable double-balloon method. Gastrointest Endosc 2001;53:216-20.

2. Costamagna G, Shah SK, Rinccioni ME, et al. A prospective trial comparing small bowel radiographs and video capsule endoscopy for suspected small bowel disease. Gastroenterology 2002;123:999-1005.

3. Madisch A, Schimming W, Kinzel F, et al. Locally advanced smallbowel adenocarcinoma missed primarily by capsule endoscopy but diagnosed by push enteroscopy. Endoscopy 2003;35:861-4 .

4. Yamamoto H, Sugano KA. New method of enteroscopy - the double-balloon method. Can J Gastroenterol 2003;17:273-4.

5. Su MY, Lin Nj, Hsu CM, et al . Doule-balloon enteroscopy: The last blind point of the gastrointestinal tract. Dig Dis Sci 2005:50;1041-5.

6. May A, Ell C. European experiences with push and pull enteroscopy in double-balloon technique (double-balloon enteroscopy). Gastrointest Endosc Clin N Am 2006;16:377-82.

7. Yamamoto H, Kita H. Double-balloon endoscopy: From concept to reality. Gastrointest Endosc Clin N Am 2006;16:347-61. 


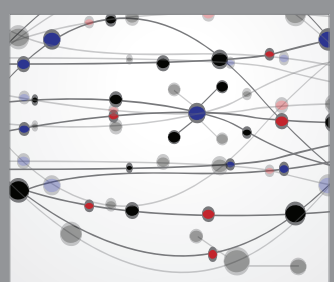

The Scientific World Journal
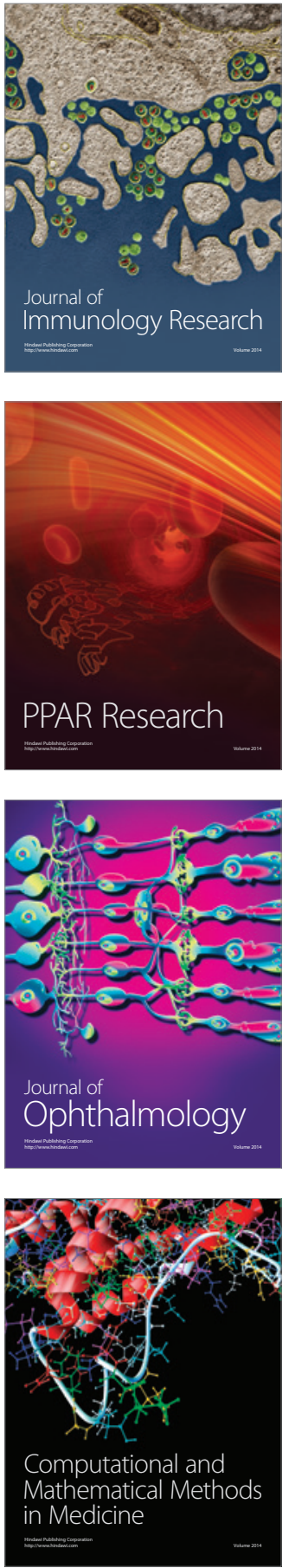

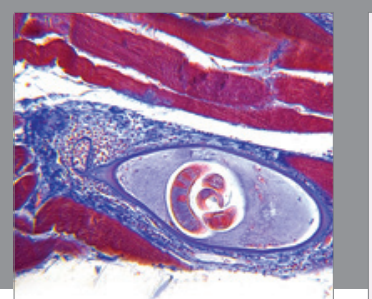

Gastroenterology Research and Practice

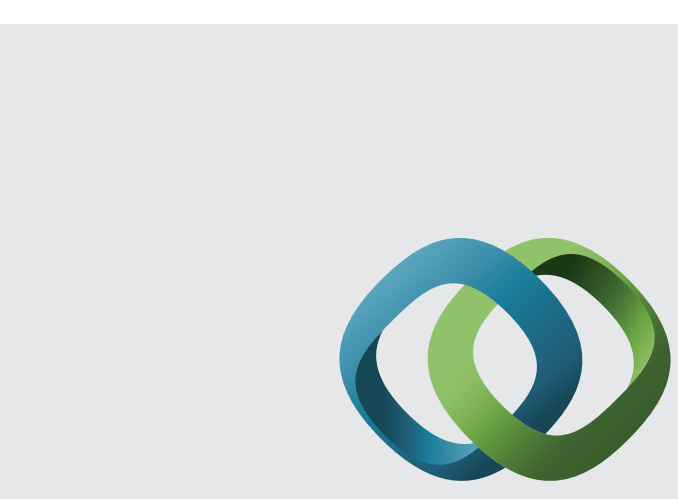

\section{Hindawi}

Submit your manuscripts at

http://www.hindawi.com
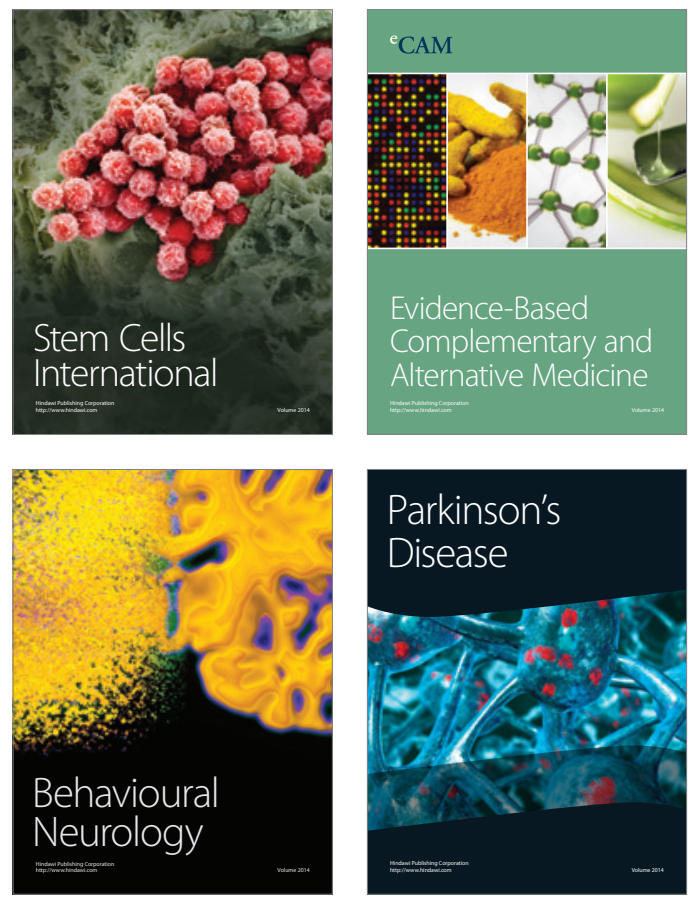
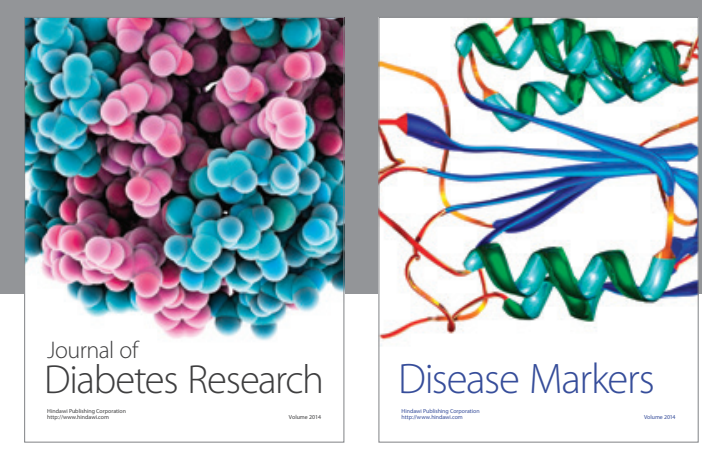

Disease Markers
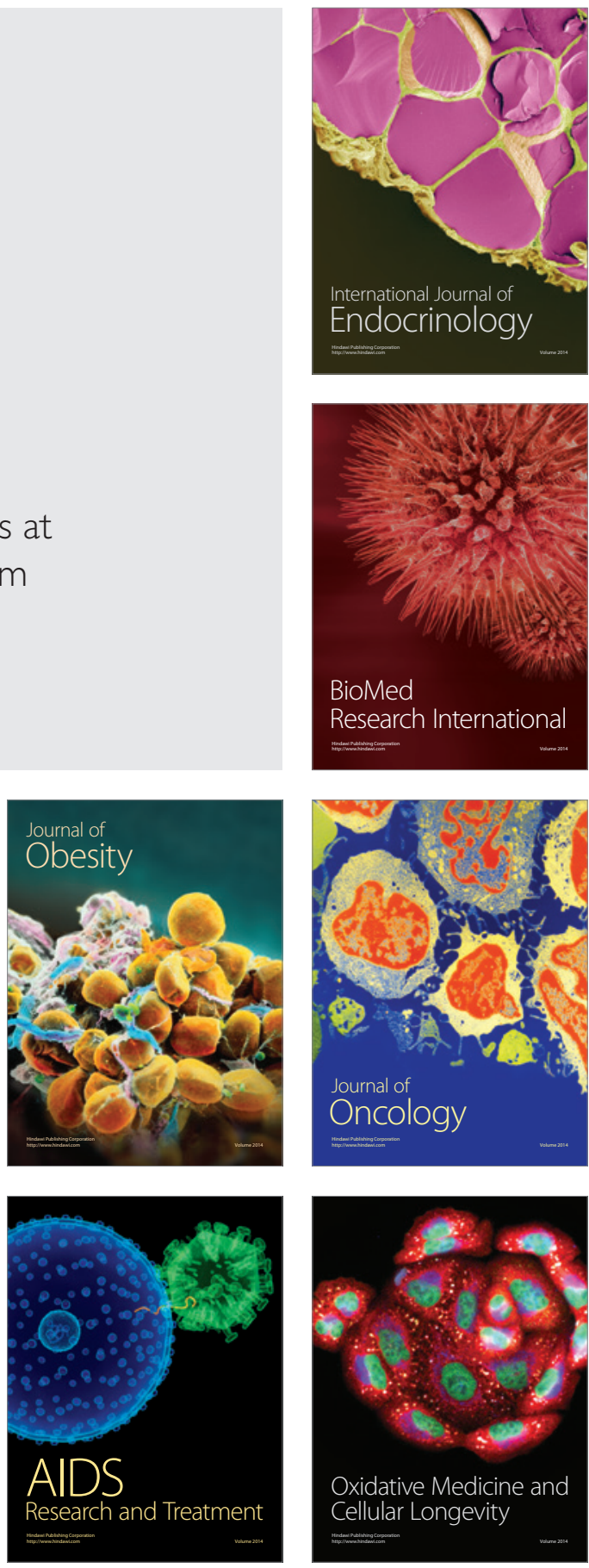